\title{
Contribution to numerical study of vehicle vertical stochastic vibration
}

\author{
Alžbeta Sapietová ${ }^{1, *}$, Milan Sága ${ }^{1}$, Dana Stančeková $^{2}$, Milan Sapieta $^{1}$ \\ ${ }^{1}$ Department of Applied Mechanics, University of Žilina, Univerzitná 1, 01026, Slovakia \\ ${ }^{2}$ Department of Industrial Engineering, University of Žilina, Univerzitná 1, 01026, Slovakia
}

\begin{abstract}
The goal of the paper is to present an application of the software MB_DYN inbuilt in MATLAB for stochastic response of the chosen vehicle computational model. The input kinematics parameters will be road irregularity with random character. The dynamic model parameters are considered as deterministic. The analysed vehicle model assumes 10 DOF. The stochastic response in time and frequency domain was solved by program MB_DYN in MATLAB using Monte Carlo method. Applying the simulation techniques the influence study of the vehicles speed and road quality in chosen points was realised.
\end{abstract}

Keywords: MATLAB, stochastic dynamics, vehicle speed, road quality

\section{Introduction}

The software MB_DYN has been successfully applied by authors several years ago in industrial and academic research areas. The software has been given for the dynamic analysis of multi-body mechanical systems. It comprises the computation of the symbolic equations of motion (using Matlab) and the simulation of the dynamic behaviour [1].

The dynamical analysis of a mechanical system starts with the modelling process. The real physical system is approximated by an idealized model $[2,3]$.

The input data for MB_DYN have to be entered in input files prepared with prompts and comments. The user has to provide only simple expressions for the description of kinematics and mass distribution with respect to arbitrary reference frames. Observation points allow the determination of position, velocity and acceleration of arbitrary points of the multibody system.

\section{Vehicle dynamic model}

Dynamic and computational model of the car was created in MB_DYN. The dynamic model (Fig. 1) was built-up from elements defined in the Table 1, 2, 3. The necessary geometry parameters of the vehicle are presented on Fig. 2.

\footnotetext{
*Corresponding author: alzbeta.sapietova@fstroj.uniza.sk

Reviewers: Juraj Gerlici, Bohuš Leitner
} 
Table 1. Six rigid bodies, of mass and rotary inertia concentrated in the centre of gravity of each body

\begin{tabular}{|c|c|c|c|c|c|c|c|}
\hline $\left.\mathbf{m}_{\mathbf{1}} \mathbf{[ k g}\right]$ & $\mathbf{m}_{\mathbf{2}}[\mathbf{k g}]$ & $\mathbf{m}_{\mathbf{3}}[\mathbf{k g}]$ & $\mathbf{m}_{\mathbf{4}}[\mathbf{k g}]$ & $\mathbf{I}_{\mathbf{x} \mathbf{}}\left[\mathbf{k g} \cdot \mathbf{m}^{\mathbf{2}}\right]$ & $\mathbf{I}_{\mathbf{y} \mathbf{1}}\left[\mathbf{k g} \cdot \mathbf{m}^{\mathbf{2}}\right]$ & $\mathbf{I}_{\mathbf{x} 3}\left[\mathbf{k g} \cdot \mathbf{m}^{\mathbf{2}}\right]$ & $\mathbf{I}_{\mathbf{y} 3}\left[\mathbf{k g} \cdot \mathbf{m}^{\mathbf{2}}\right]$ \\
\hline 1130 & 42.5 & 25 & 42 & 504 & 1840 & 0.8 & 0.5 \\
\hline
\end{tabular}

Table 2.Linear springs elements

\begin{tabular}{|c|c|c|c|c|}
\hline $\mathbf{k}_{\mathbf{1}}[\mathbf{N} / \mathbf{m}]$ & $\mathbf{k}_{\mathbf{2}}[\mathbf{N} / \mathbf{m}]$ & $\mathbf{k}_{\mathbf{3}}[\mathbf{N} / \mathbf{m}]$ & $\mathbf{k}_{\mathbf{4}}[\mathbf{N} / \mathbf{m}]$ & $\mathbf{k}_{\mathbf{5}}[\mathbf{N} / \mathbf{m}]$ \\
\hline 200000 & 15500 & 23300 & 250000 & 180000 \\
\hline
\end{tabular}

Table 3. Damping elements

\begin{tabular}{|c|c|c|}
\hline $\mathbf{b}_{2}\left[\mathbf{k g m}^{2} \mathbf{s}^{-1}\right]$ & $\mathbf{b}_{\mathbf{3}}\left[\mathbf{k g m}^{\mathbf{2}} \mathbf{s}^{-1}\right]$ & $\mathbf{b}_{\mathbf{4}}\left[\mathbf{k g m}^{2} \mathbf{s}^{-1}\right]$ \\
\hline 1130 & 42.5 & 25 \\
\hline
\end{tabular}

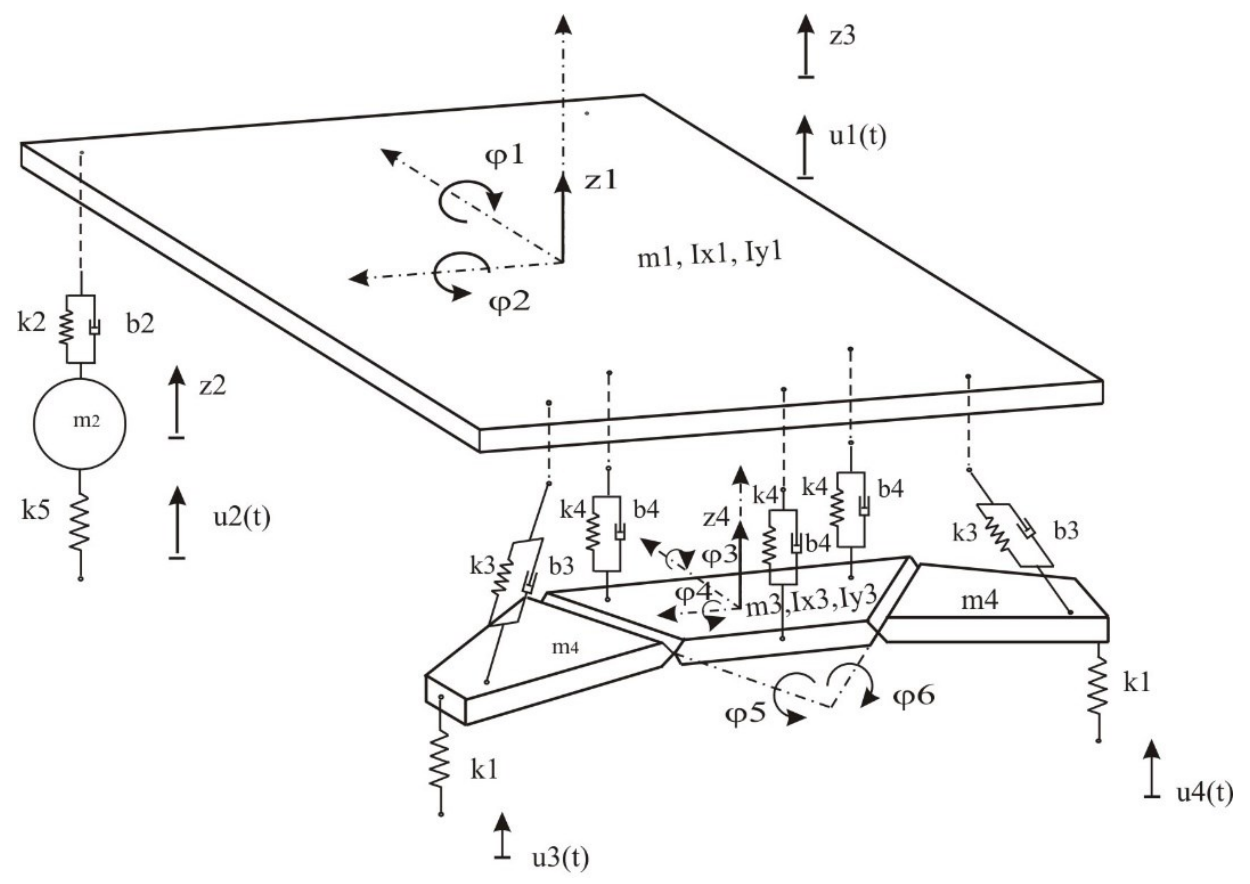

Fig. 1. Dynamic model of vehicle 


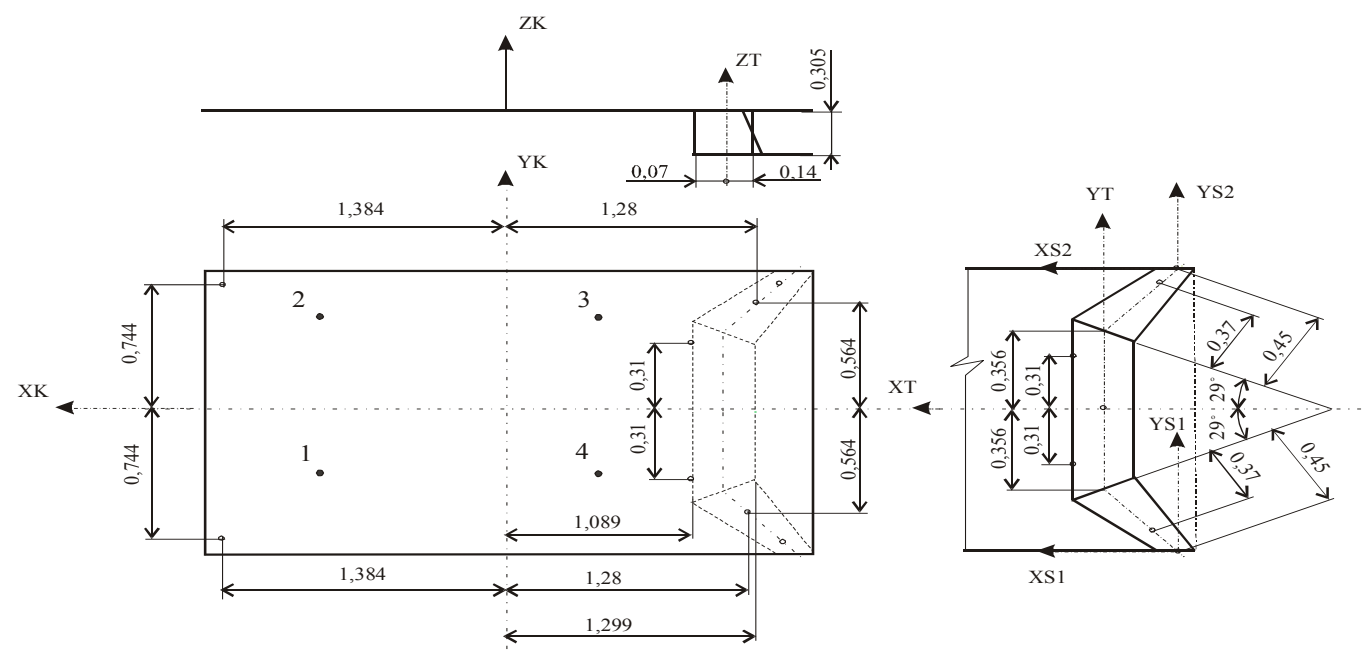

Fig. 2. Geometry of vehicle

\section{Description of kinematic excitation}

Generally we can found three different sorts of roadway roughness, i.e.

- local extreme unevenness,

- regular unevenness,

- irregular unevenness.

The two unevennesses mentioned first are deterministic and may be described geometrically. The irregular unevenness however are random and their probabilistic idealization involves the use of the theory of stochastic processes [4-6].

An appropriate mathematical modelling of these irregularities of the pavement surface can be based on the concept of stationary stochastic process, whose probabilistic structure can be conveniently described by the corresponding power spectral density function (PSD) [7-10]. According to the International Organization for Standardization (ISO) specifications, this power spectrum can be represented by an exponential function

$$
S(\Omega)=S\left(\Omega_{0}\right) \cdot\left(\frac{\Omega}{\Omega_{0}}\right)^{-w} .
$$

The coefficient $S\left(\Omega_{0}\right)$ and the exponent $w$ are two parameters that depend on the characteristics of the roadway roughness [11-18]. Table 4 presents usual values of $S\left(\Omega_{0}\right)$ for different qualities of pavement, assuming $\Omega_{0}=1\left(\mathrm{~m}^{-1}\right)$ and $w=2$.

The generation of an artificial discrete profile of the pavement surface can be performed based on the previous knowledge of the power spectral density function $S(\Omega)$, assuming such a profile given by a Fourier series, as follows:

$$
u_{i+1}=u_{i}+\Delta x \cdot \sqrt{S_{0}} \cdot \Omega_{0} \cdot w_{i}
$$


where function $\mathrm{w}_{\mathrm{i}}(\mathrm{t})$ is a zero mean Gaussian white noise process with the power spectral density $S=1\left(\mathrm{~m}^{2} \mathrm{~s}^{-3}\right)$ :

$$
w(t)=\sum_{i=1}^{n} \sqrt{2 \cdot \Delta \Omega_{i}} \cdot \cos \left(\Omega_{i} \cdot x-\theta_{i}\right),
$$

Parameter $\Omega_{i}$ is a frequency within the interval of relevant spectral content, $\theta i$ is random phase angle with uniform distribution in the interval $[0,2 \pi], \Delta \Omega_{i}$ is a frequency increment and $n$ is the total number of harmonic waves considered. The simulation of the random response of the vehicle was realized in 8000 discrete points. These simulated road distance was $2 \mathrm{~km}$.

Table 4. Usual values of $S\left(\Omega_{0}\right)$ for different qualities of pavement, assuming $\Omega_{0}=1\left(\mathrm{~m}^{-1}\right)$ and $w=2$.

\begin{tabular}{|c|c|c|c|}
\hline \multirow{2}{*}{$\begin{array}{l}\text { Quality of } \\
\text { pavement }\end{array}$} & \multicolumn{3}{|c|}{$\mathbf{S}\left(\boldsymbol{\Omega}_{\mathbf{0}}\right)\left[\mathbf{c m}^{\mathbf{3}}\right]$} \\
\hline very good & lower limit & mean value & upper limit \\
\hline good & 0.5 & 1 & 2 \\
\hline average & 2 & 4 & 8 \\
\hline poor & 8 & 16 & 32 \\
\hline very poor & 32 & 64 & 128 \\
\hline
\end{tabular}

\section{Results}

The final goal of this study was to realise the influence analyse of the vehicles speed and roadway roughness on the acceleration in chosen points of the car. The grafic presentation of the results is on Figs. 3, 4, 5, and 6. On illustrate, the power spectral density for speed $60 \mathrm{~km} / \mathrm{h}$ and third degree of roadway quality is shown on figures 7 and 8 . The study can attend as a guide for signification analysis in vehicle dynamics.

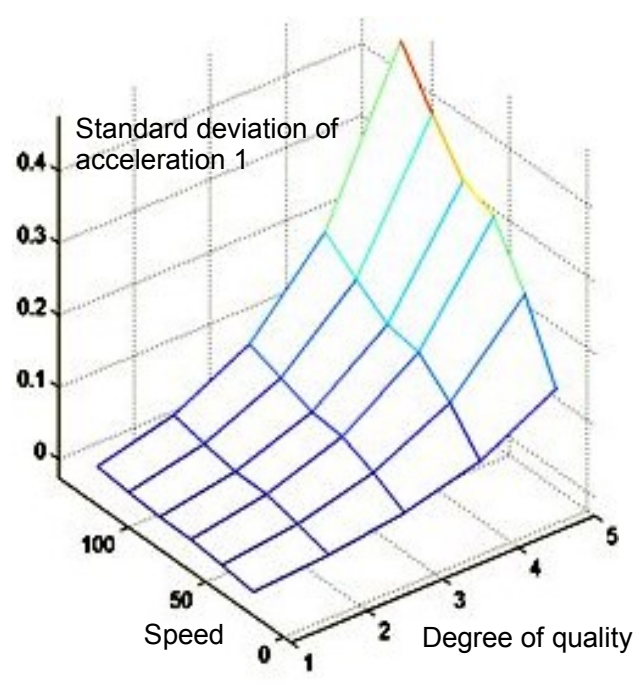

Fig. 3. Influence of the speed and roadway roughness on the acceleration

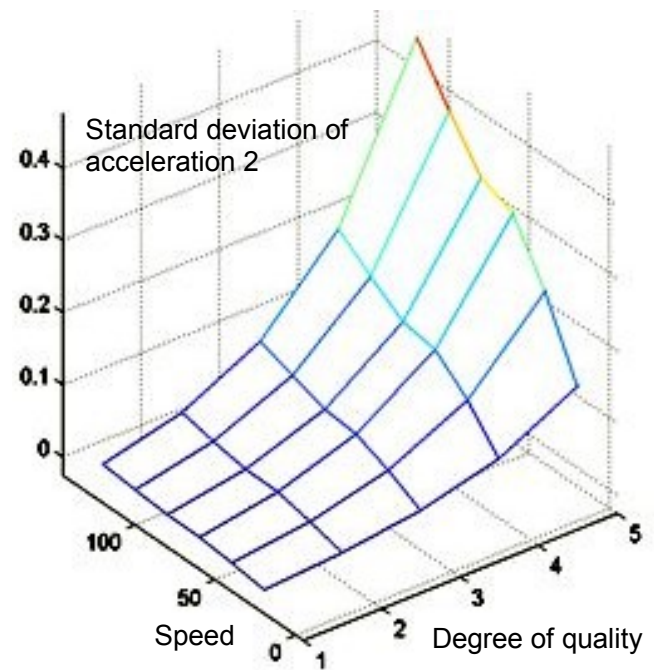

Fig. 4. Influence of the speed and roadway roughness on the acceleration 


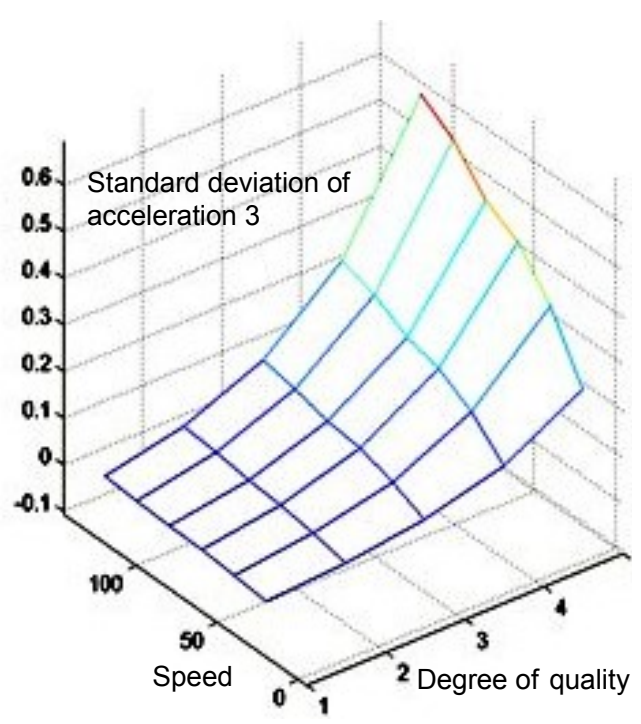

Fig. 5. Influence of the speed and roadway roughness on the acceleration

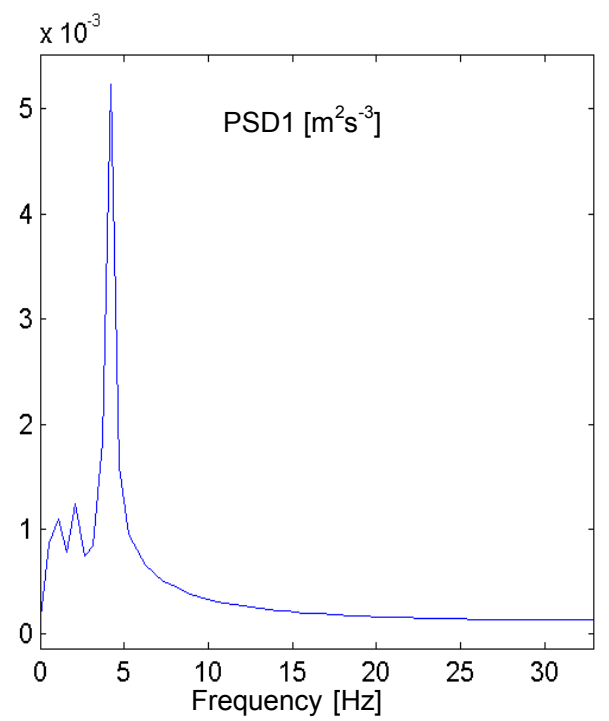

Fig. 7. Power spectral density of acceleration in point 1

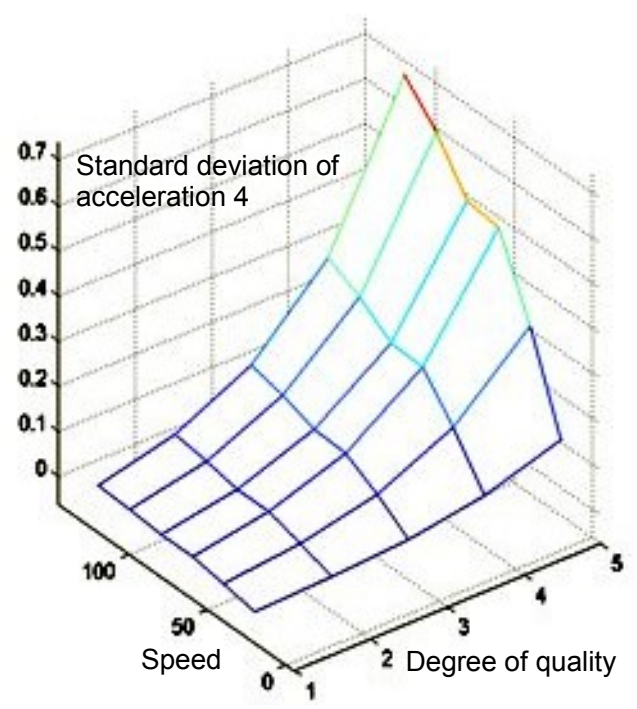

Fig. 6. Influence of the speed and roadway roughness on the acceleration

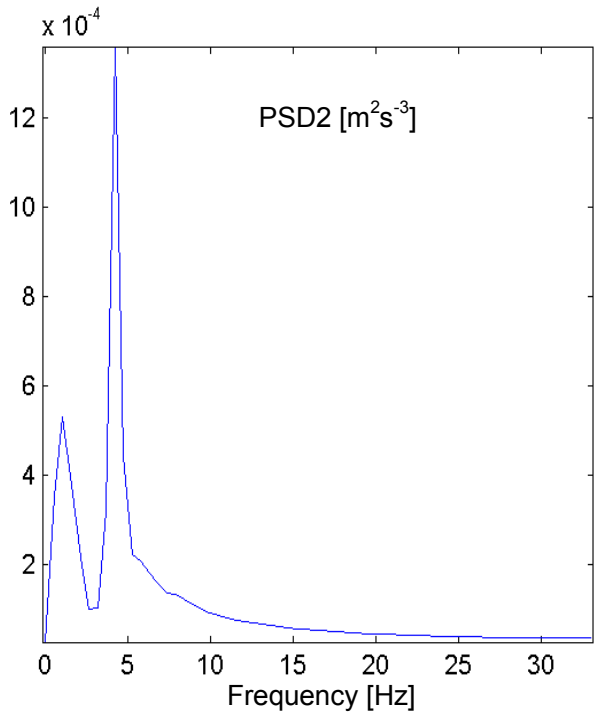

Fig. 8. Power spectral density of acceleration in point 2

\section{Conclusion}

The paper has been form on the base of the collaboration of departments of mechanics of universities in Zilina and Stuttgart. The aim was to propose the methodology of the solution of multibody dynamics systems by software packages NB_DYN. The main scientific goal was to present numerical study of the speed of movement and road quality influence on car 
vertical vibrations. The study can attend as a guide for signification analysis in vehicle dynamics.

The part of the results of this work was supported by grants VEGA 1/0795/16 and KEGA 017ŽU$4 / 2017$.

\section{References}

1. W. Schiehlen, W, Multibody Systems Handbook. Springer-Verlag Berlin Heidelberg, 432 (1990)

2. A. Sapietová, M. Sága, P. Novák, R. Bednár, J. Dižo, Design and application of multisoftware platform for solving of mechanical multi-body system problems. Mechatronics: Recent technological and scientific advances, 345-354 (2011)

3. J. Gerlici, T. Lack, Railway wheel and rail head profiles development based on the geometric characteristics shapes. Wear: an international journal on the science and technology of friction, lubrication and wear 271 (1-2), 246-258 (2011)

4. J. Gerlici, T. Lack, Modified HHT method for vehicle vibration analysis in time domain utilisation. Applied mechanics and materials 486, 396-405 (2014)

5. J. Gerlici, T. Lack, J. Harušinec, Realistic simulation of railway operation on the RAILBCOT test stand. Applied mechanics and materials 486, 387-395 (2014)

6. J. Ondrouch, P. Ferfecki, Z. Poruba, Active vibration reduction of rigid rotor by kinematic excitation of bushes of journal bearings. Metalurgija 49 (2), 107-110 (2010)

7. J. Flizikowski, M. Macko, J. Czerniak, A. Mroziński, Implementation of genetic algorithms into development of mechatronic multi-edge's grinder design. ASME 2011 Int. Mech. Eng. Congress and Exposition, IMECE 7, 1227-1235 (2011)

8. M. Macko, J. Flizikowski, Z. Szczepański, K. Tyszczuk, G. Śmigielski, A. Mroziński, J. Czerniak, A. Tomporowski, CAD/CAE applications in mill's design and investigation. Proceedings of the 13th International Scientific Conference on Computer Aided Engineering - Editors: Rusinski, Eugeniusz, Pietrusiak, Damian (Eds.). Series Title: Lecture Notes in Mechanical Engineering, Part F 10, 343-351 (2017)

9. T. Domanski, A. Bokota, Numerical analysis of phenomena during progressive hardening of tool steel elements for cold work. Procedia Engineering 177, 70-77 (2017)

10. T. Domanski, A. Bokota, W. Piekarska, M. Kubiak, Nmerical analysis of microstructure and stress generated by heat treated of steel elements. Conference Proceedings, 642-647 (2015)

11. M. Łazarska, T. Woźniak, Z. Ranachowski, A. Trafarski, G. Domek, Analysis of acoustic emission signals at austempering of steels using neural networks. Metals and Materials International 23 (3), 426-433 (2017)

12. M. Dudziak, G. Domek, A. Kołodziej, K. Talaśka, Contact Problems Between the Hub and the Shaft with a Four-Angular Shape of Cross-Section for Different Angular Positions. Applied Mechanics and Materials 816, 54-62 (2015)

13. J. Vavro Jr., J. Vavro, P. Kováčiková, R. Bezdedová, Kinematic and dynamic analysis of planar mechanisms by means of the SolidWorks software. Procedia Engineering 177, 476-481 (2017)

14. J. Vavro Jr., J. Vavro, P. Kováčiková, R. Bezdedová, Kinematic and dynamic analysis of the manipulator for removal of rough tyres. Procedia Engineering 136, 120-124 (2016) 
15. R. Halama, R. Fajkos, P. Matusek, et al., Contact defects initiation in railroad wheels Experience, experiments and modelling. $8^{\text {th }}$ Conference on Contact Mechanics and Wear of Rail/Wheel Systems 271 (1-2), 174-185 (2011)

16. M. Handrik, M. Vaško, P. Kopas, V. Mózer, The Linear and Nonlinear Stability Loss of Structures due to Thermal Load. Procedia Engineering 136, 359-364 (2016)

17. P. Kopas, L. Jakubovičová, M. Vaško, M. Handrik, Fatigue Resistance of Reinforcing Steel Bars. Procedia Engineering 136, 193-197 (2016)

18. M. Kubiak, T. Domanski, V. Dekys, et al., Measurement of strain during tension test of welded joint using multi-camera $3 D$ correlation system. Procedia Engineering 177, 107-113 (2017) 